\title{
USE OF BOUNDING ANALYSES TO ESTIMATE THE PERFORMANCE OF A SEISMICALLY ISOLATED STRUCTURE
}

\author{
Gökhan ÖZDEMİR ${ }^{1, *}$, Özgür AVŞAR ${ }^{1}$ \\ ${ }^{1}$ Department of Civil Engineering, Anadolu University, 26555 Eskişehir, Turkey
}

\begin{abstract}
Current design approach for seismic isolated structures is to perform bounding analyses. These analyses provide an envelope for the response of the seismic isolated structure rather than focusing on the actual performance. In this study, the success of bounding analyses to estimate performance of a seismic isolated structure, in which the isolation is provided by means of lead rubber bearings (LRBs), is evaluated in a comparative manner. For this purpose, nonlinear response history analyses were performed under the effect of bidirectional ground motion excitations. In bounding analyses, non-deteriorating hysteretic representations were used to model the hysteretic behavior of LRBs. On the other hand, to estimate the actual performance of both the superstructure and isolator units, deteriorating hysteretic idealizations were employed. The deterioration in strength of LRBs was defined as a function of temperature rise in the lead core. The analyzed structure is an existing seismically isolated hospital building and analytically modeled in accordance with its reported design properties for both isolation units and superstructure. Results obtained from analyses where LRBs are idealized by both deteriorating and non-deteriorating hysteretic representations are used in the comparisons. The response quantities used in the comparisons are maximum isolator displacement, maximum isolator force, maximum absolute floor acceleration, and maximum relative story displacements. In an average sense, bounding analyses is found to provide conservative estimates for the selected response quantities and fulfills its intended purpose. However, it is revealed that there may be individual cases where bounding analyses fails to provide a safe envelope.
\end{abstract}

Key words: Seismic isolation, Lead rubber bearing, Bidirectional analyses, Strength deterioration, Structural response

\section{INTRODUCTION}

A lead rubber bearing (LRB), subjected to cyclic motion, undergoes a gradual reduction in strength that results in a deteriorating hysteretic force-deformation relation [1]. Basis of such variation in strength of isolators has been identified so far by the effects of loading history, aging, contamination and heating. In order to account for that variation in strength of isolator, the current design approach is to perform bounding analyses namely, lower bound and upper bound analyses [2,3]. Such a modeling approach is an attempt to provide envelopes for response quantities of LRBs, and has emerged due to lack of ability to model the actual deteriorating hysteretic behavior of LRBs. In bounding analyses, hysteretic behavior of LRBs are represented by non-deteriorating bilinear force-deformation relations based on the data obtained from tests under cyclic motions with amplitudes compatible with the design spectra. Generally, lower bound characteristics are used to mimic the behavior of LRBs under high amplitude, large number of cyclic motions whereas upper bound properties are used to idealize the behavior of LRBs subjected to low amplitude, small number of cyclic motions.

To be able to model the actual response of LRBs, two recent studies conducted by Kalpakidis and Constantinou [4,5] investigated the deterioration in hysteretic behavior of LRBs. They revealed that the main parameter that controls the reduction in strength of LRBs is the rise in temperature of lead core during cyclic motion. Accordingly, authors proposed and verified an analytical model that is capable of representing the deterioration in strength of LRBs as a function of temperature rise in the lead core. As a result, a new research area emerged to assess the efficiency of existing design approach, which provides envelopes for response quantities of LRBs, compared to actual behavior of 
isolators. However, yet, there are only a few studies that utilized the model proposed by Kalpakidis and Constantinou [4,5] to scrutinize the effect of lead core heating on the response of LRBs [6-10]. Among these, Ozdemir et al. [6] investigated the response of LRBs in a seismic isolated bridge by a parametric study. Authors studied the effects of isolation period and characteristic strength to weight ratio on lead core heating of LRBs through comparisons with the results obtained from bounding analyses. Ozdemir and Dicleli [7] studied lead core heating effect on the hysteretic behavior of LRBs subjected to both simulated and recorded near-fault ground motions for a single-degree-of freedom (SDOF) system. Parameters considered by the authors were number of cycles, distance from fault rupture and magnitude of motion. In both studies, it is revealed that the amount of overestimation provided by bounding analyses for response quantities of LRBs depends highly on both isolator properties and ground motion characteristics. Ozdemir [8] proposed a series of formulations, which take into account the deterioration in strength of LRBs, to determine the equivalent damping ratio of LRBs to be used in simplified method of analysis. All of the studies discussed so far were conducted under unidirectional excitations. On the other hand, Ozdemir [9] and Ozdemir and Bayhan [10] studied the deteriorating hysteretic behavior of LRBs under bidirectional ground motion excitations. Results of these studies showed that there is an additional amplification in MIDs due to increased lead core temperatures apart from the effect of coupling. However, these studies have solely focused on the response of isolators and not considered the discussions related to response of superstructures.

On the other hand, there are studies that focused on the superstructure response of seismically isolated structures. For instance, Providakis [11] investigated the variation in the inter-story drift ratio of the superstructures, which are base isolated by LRBs, under the effect of near- and far-fault earthquakes. Similarly, Yang et al. [12] examined the superstructure response of various seismically isolated systems regarding the performance of equipment hosted in the structure. Authors emphasized that together with the isolation units, superstructure plays also an important role in the protection of acceleration sensitive equipment in the base isolated buildings. Although the above mentioned studies considered LRBs as isolator units, they did not consider the strength deterioration in LRBs due to lead core heating.

Furthermore, in all of the studies cited here, either the superstructure or the isolation systems considered in the analytical models were imaginary systems used to represent probable cases. None of these studies address the performance of an existing LRB isolated structure defined as a composition of actual characteristics of both isolation system and superstructure.

The present study aims to assess the ability of bounding analyses in providing safe envelopes for response quantities of an existing LRB isolated structure subjected to bidirectional ground motion excitations. For this purpose, an LRB isolated structure, the Erzurum Hospital, is considered and analyzed for both deteriorating and non-deteriorating (bounding analyses) representations of LRBs. The results obtained from bounding analyses are compared with the actual response of the building that is assumed to be the one obtained from analyses where deteriorating hysteretic representations are used to idealize the employed LRBs. It is to be noted that the analytical modeling of LRBs are based on the actual test results conducted for the Erzurum Hospital building's LRBs. Comparisons are made in terms of maximum isolator displacements (MIDs) and maximum isolator forces (MIFs) for isolation units, and maximum absolute floor accelerations and maximum relative story displacements for the superstructure.

\section{ANALYZED STRUCTURE: ERZURUM HOSPITAL}

Erzurum is located in the north-east part of Turkey. As shown in Figure 1, the investigated Erzurum Hospital is within the close vicinity of active faults. These faults constitute the eastern fault segments of North Anatolian Fault (NAF) and East Anatolian Fault (EAF) with a strike-slip faulting mechanism in northeastern region of Turkey. The Erzurum Hospital is 4km away from the Erzurum Fault [13]. In 
Figure 1, location of the Erzurum Hospital is designated by a black star whereas red lines represent the active fault segments. According to the current Earthquake Zoning Map of Turkey [14], the Erzurum Hospital is located in the second seismic zone, which has the second highest seismicity among the five earthquake hazard zones in Turkey.

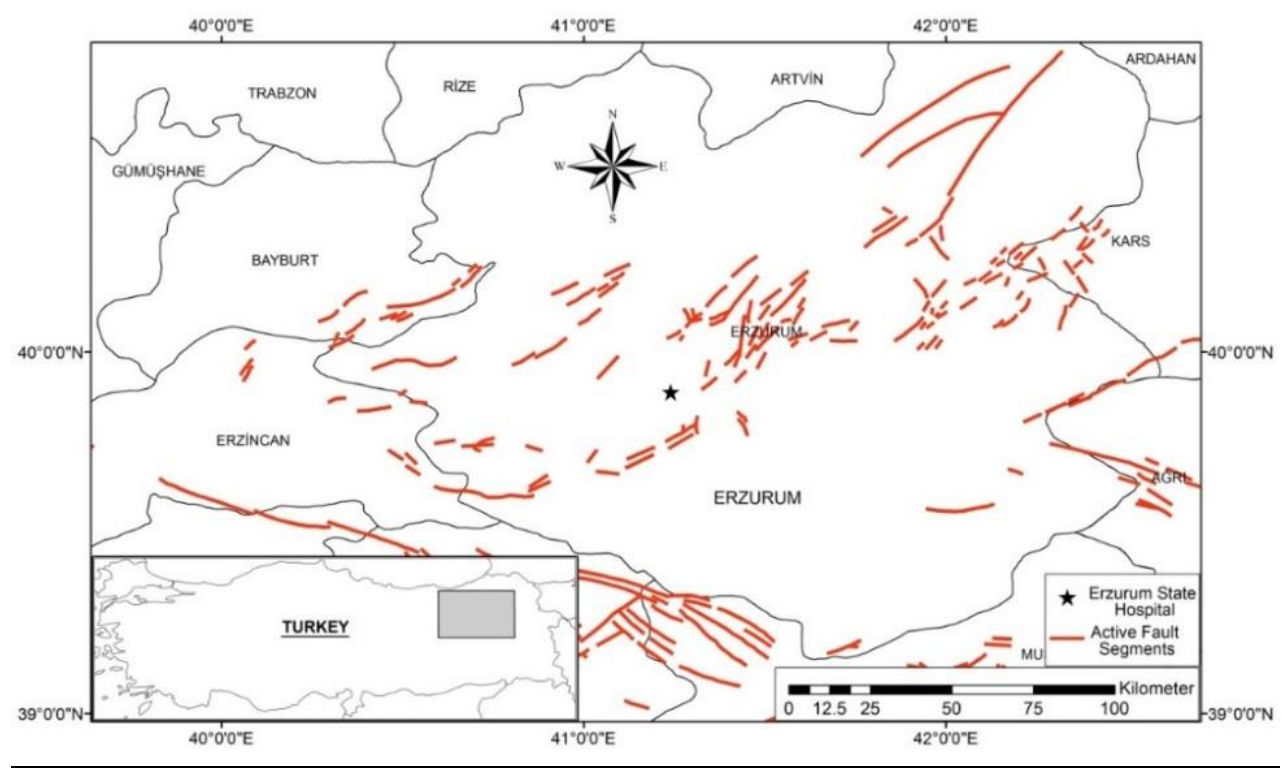

Figure 1. Active fault segments around the Erzurum Hospital

The Erzurum Hospital is composed of reinforced concrete (RC) frame system and has plan dimensions of $164 \mathrm{~m} \times 146 \mathrm{~m}$ with a total height of $35.4 \mathrm{~m}$ from isolation level to the highest story level (Figure 2). The building has 2 basement stories, 1 ground story, and 4 normal stories and a penthouse, a total of 8 stories above the isolation level. The structure has a dual system with beam-column frames and structural walls. Seismic isolation of the Erzurum Hospital is provided by 386 isolation units composed of both LRB (323) and natural rubber bearings (63) (NRBs) Distribution of these isolation units is shown in Figure 3. The geometrical properties of each bearing type are given in Table 1. The total weight of the structure is $2336 \mathrm{MN}$ and the isolation period, based on the post-yield period of isolator $k_{d}$ (see Figure 5.b), is 3.0s.

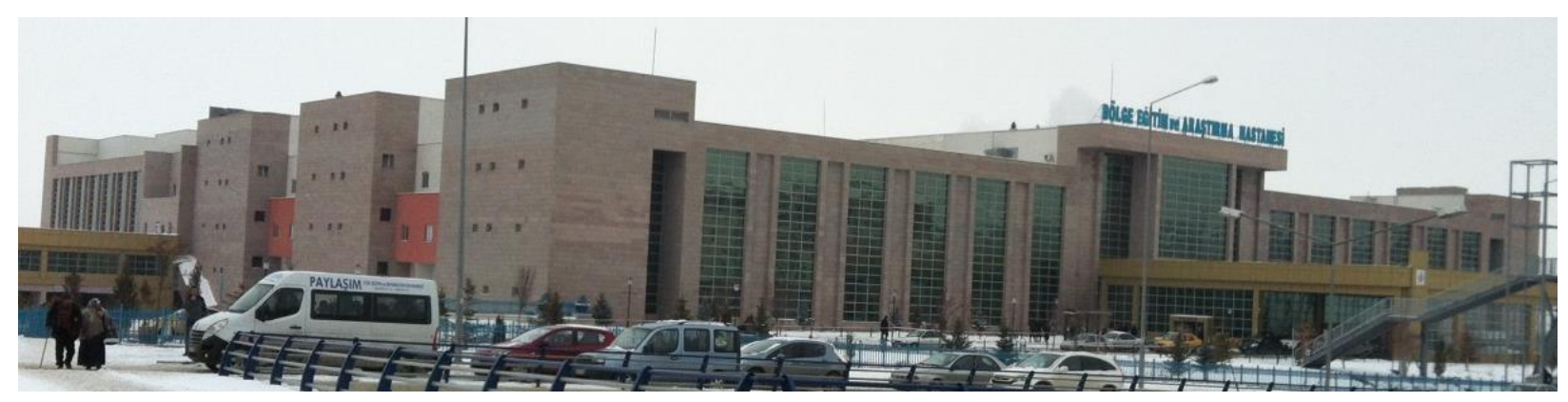

Figure 2. General view of the Erzurum Hospital 


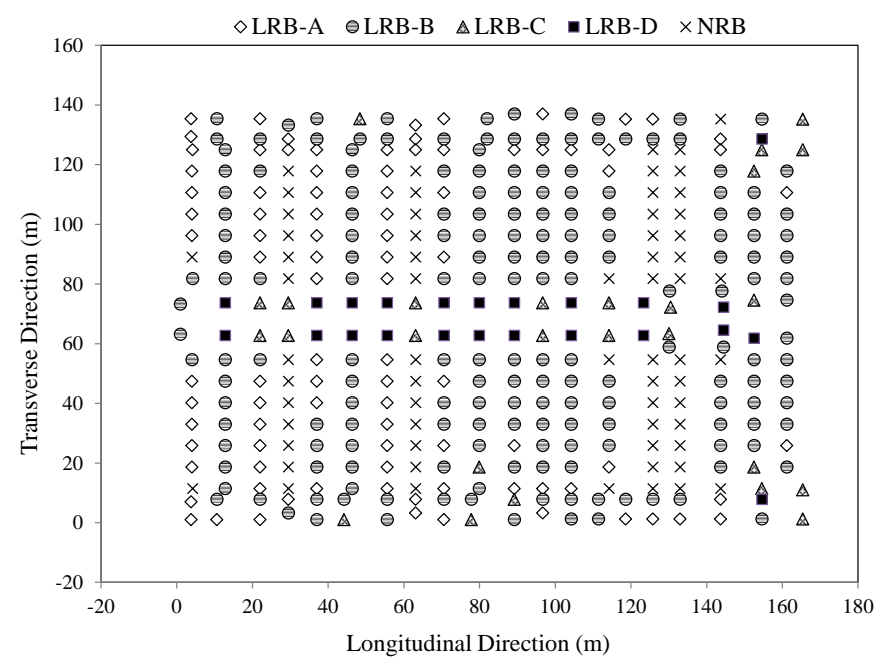

Figure 3. Distribution of isolator units at the isolation level of the building (adopted from [16])

The 3-dimensional (3-D) analytical model of the building's structural system was generated by Open System for Earthquake Engineering Simulation, OpenSees [15]. The RC beam, column and wall members were modeled by elastic frame elements. Since the only nonlinearity takes place at the isolation level, the isolator units were modeled with their nonlinear force-deformation properties. Modeling of isolator units in Opensees [15] was accomplished by means of ZeroLength elements and assigned material class is capable of representing the deteriorating hysteretic behavior of LRBs under bidirectional excitations. The 3-D analytical model of the analyzed structure is given in Figure 4.

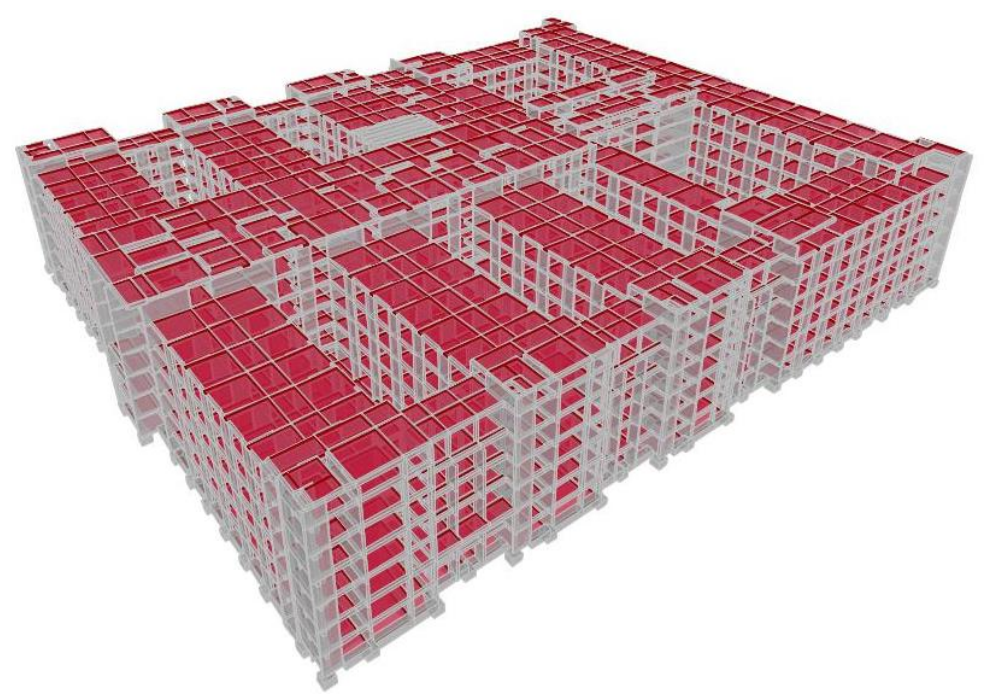

Figure 4. 3D analytical model of Erzurum Hospital 


\section{PROPERTIES OF THE BEARINGS USED IN DESIGN OF THE ERZURUM HOSPITAL}

This section presents the properties of the bearings used in seismic base isolation of the Erzurum Hospital where both LRBs and NRBs were used in a joint form. Employed LRBs are composed of 4 distinct sizes with diameters $850 \mathrm{~mm}, 950 \mathrm{~mm}, 1038 \mathrm{~mm}, 1155 \mathrm{~mm}$ and named as LRB-A, LRB-B, LRB-C, LRB-D, respectively. The distribution of each bearing type at the isolation level is given in Figure 3. The NRB used in the isolation of the Erzurum Hospital has a diameter of $850 \mathrm{~mm}$. Geometrical features of the employed bearings are given in Table 1. LRB-A, LRB-B and NRB are composed of 29 layers of rubber and 28 layers of steel shim plates with thicknesses of $7 \mathrm{~mm}$ and 3 $\mathrm{mm}$, respectively. On the other hand, LRB-C and LRB-D have 26 layers of rubber and 25 layers of steel shim plates with thicknesses of $8 \mathrm{~mm}$ and $5 \mathrm{~mm}$, respectively.

Table 1. Geometrical features of the employed bearings

\begin{tabular}{|c|c|c|c|c|c|c|c|c|c|}
\hline \multirow{2}{*}{ Bearing } & \multirow{2}{*}{$\begin{array}{c}\boldsymbol{D} \\
(\mathbf{m m})\end{array}$} & \multirow{2}{*}{$\begin{array}{c}\boldsymbol{h} \boldsymbol{h} \\
(\mathbf{m m})\end{array}$} & \multicolumn{3}{|c|}{$\boldsymbol{F y}(\mathbf{k N})$} & \multicolumn{3}{|c|}{$\boldsymbol{\alpha}\left(\boldsymbol{k}_{d} / \boldsymbol{k}_{\boldsymbol{e}}\right)$} \\
\cline { 5 - 11 } & & & $\mathbf{L B}^{\mathbf{a}}$ & $\mathbf{U B}^{\mathbf{b}}$ & $\mathbf{T I}^{\mathbf{c}}$ & $\mathbf{L B}^{\mathbf{a}}$ & $\mathbf{U B}^{\mathbf{b}}$ & $\mathbf{T I}^{\mathbf{c}}$ \\
\hline LRB-A & 850 & 220 & 287 & 333.3 & 461.5 & 409.4 & 0.088 & 0.094 & 0.071 \\
\hline LRB-B & 950 & 254 & 287 & 442.1 & 611.9 & 534.4 & 0.083 & 0.089 & 0.068 \\
\hline LRB-C & 1038 & 280 & 333 & 535.7 & 741.2 & 658.8 & 0.080 & 0.086 & 0.065 \\
\hline LRB-D & 1155 & 305 & 333 & 638.4 & 883.7 & 784.6 & 0.084 & 0.090 & 0.069 \\
\hline NRB & 850 & - & & 48.7 & 77.9 & - & 0.389 & 0.361 & - \\
\hline
\end{tabular}

In Table $1, D$ is the diameter of the bearing, $d$ is the diameter of the lead core, and $h_{L}$ is the height of the lead (see Figure 5.a). $F_{y}, k_{d}, k_{e}$ are the yield force, post-yield stiffness and elastic stiffness of the idealized hysteretic behavior of LRB as shown in Figure 5.b. $\alpha$ is the dimensionless constant that gives the relation between elastic stiffness, $k_{e}$, and post-yield stiffness, $k_{d}$. In Figure 5.b, $Q$ is the characteristic strength of the LRB and $U_{y}$ is the yield displacement corresponding to the yield force, $\mathrm{F}_{\mathrm{y}}$.
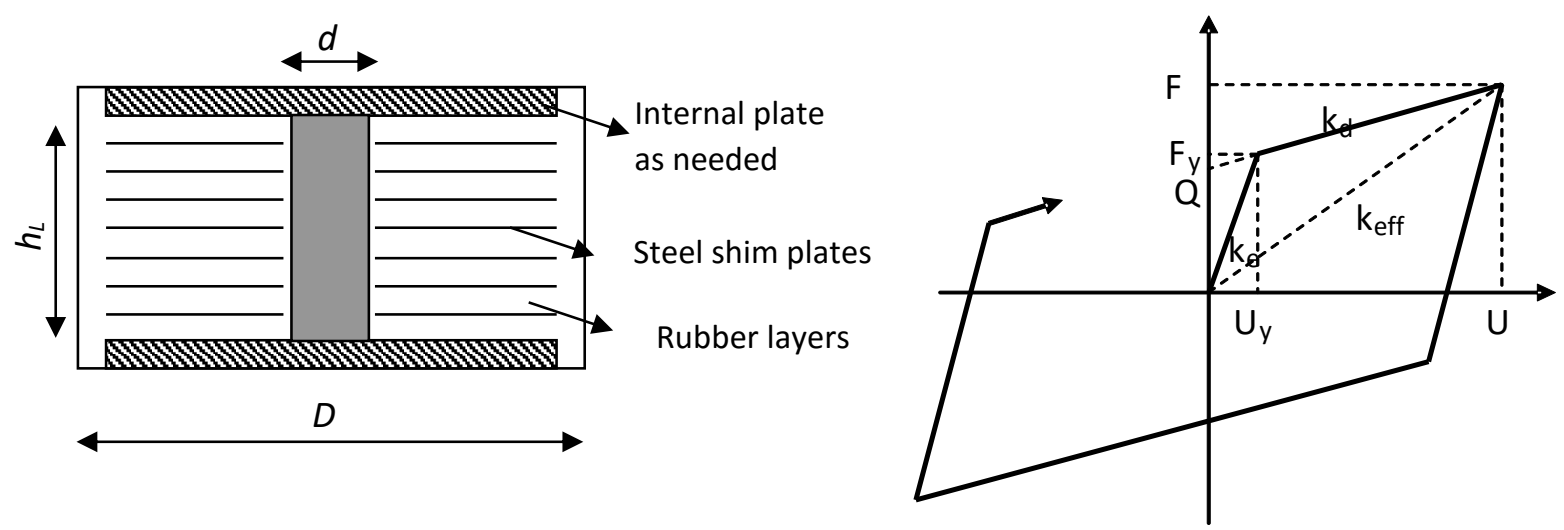

Figure 5. Characteristics of lead rubber bearings 
Table 1 clearly indicates that there is a significant difference between the yield strengths of LRBs and NRB. In the design and analysis of seismic isolation system for the Erzurum Hospital, Erdik and Constantinou [16] reported that since the yield strength of NRBs is so small compared to its LRB counterparts, accuracy in the calculation of NRBs is not that much important as for LRBs. Hence, only LRBs are considered in the following discussions related to lower and upper bound properties. However, the corresponding yield strengths and post yield stiffness to elastic stiffness ratios of the employed NRB are given for both lower and upper bound conditions in Table 1.

\subsection{Reported Lower Bound Properties}

The effective yield stress of lead that represents the lower bound characteristics, $\sigma_{Y, L B}$, is calculated by taking the average of yield stresses at the first three cycles of motion. In the design of isolation bearings, $\sigma_{Y, 3}$ was calculated as $8 \mathrm{MPa}$ based on the test results of considered LRBs [16]. To obtain $\sigma_{Y, L B}, \sigma_{Y, 3}$ was multiplied with the minimum values of property modification factors $\lambda_{t}, \lambda_{a}$ and $\lambda_{\text {scrag }}$ which are all equal to 1.0 [16]. Thus, the effective yield stress of lead core used in lower bound analyses, $\sigma_{Y, L B}$, was determined as $8 \mathrm{MPa}$. Consequently, the corresponding yield strength and postyield stiffness values for LRBs are presented in Table 1 .

\subsection{Reported Upper Bound Properties}

The yield strength of an LRB that constitutes the upper bound property is calculated as a function of the effective yield stress of lead obtained from the first cycle of hysteretic behavior, $\sigma_{Y, 1}$. Test results conducted with the LRBs under consideration showed that the initial yield stress of lead, $\sigma_{Y, 1}$ is 10 $\mathrm{MPa}$ [16]. The yield stress of lead used in upper bound analyses, $\sigma_{Y, U B}$, is calculated by multiplying the $\sigma_{Y, 1}$ by corresponding property modification factors $\lambda_{t}, \lambda_{a}$ and $\lambda_{\text {scrag }}$. Values for modification factors $\lambda_{t}$, $\lambda_{a}$ and $\lambda_{\text {scrag }}$ were reported as 1.1, 1.0 and 1.0, respectively by Erdik and Constantinou [16]. As a result, $\sigma_{Y, U B}$, is obtained as $11 \mathrm{MPa}$. The yield strength of LRBs to be used in upper bound analyses was determined based on $\sigma_{Y, U B}=11 \mathrm{MPa}$ and listed in Table 1, namely, UB.

\section{DETERIORATING HYSTERETIC BEHAVIOR OF LRBS AND CORRESPONDING PLASTICITY MODEL}

The force-deformation relation given in Figure 5.b is a non-deteriorating representation used to idealize the hysteretic behavior of isolators subjected to cyclic motion. Such hysteretic representations are used in bounding analyses with distinct properties representative of lower and upper bound cases. The purpose of performing bounding analyses is to define an envelope for response quantities of isolated structure by considering probable minimum and maximum values for modeling the strength of isolators. This modeling technique is an attempt to represent the deterioration in strength of isolators observed under cyclic motion. Basis of such deterioration in strength of isolators has been identified so far by the effects of loading history, aging, contamination and heating. However, Kalpakidis and Constantinou [4,5] showed that increase in the temperature of lead core is the main reason for the deterioration in strength of lead rubber bearings. Accordingly, they proposed a mathematical model that is capable of calculating the instantaneous lead core temperature and updating the strength of LRB instantly. In their model, deterioration in strength of an LRB is achieved by reducing the initial yield stress of lead as a function of lead core temperature, $T_{L}$, and it is defined by the following set of equations:

$$
\sigma_{Y}\left(T_{L}\right)=\sigma_{Y, 1} \cdot \exp \left(-E_{2} \cdot T_{L}\right)
$$

where 


$$
\begin{aligned}
& \dot{T}_{L}=\frac{\sigma_{Y L}\left(T_{L}\right) \cdot|Z \cdot \dot{U}|}{\rho_{L} \cdot c_{L} \cdot h_{L}}-\frac{k_{s} \cdot T_{L}}{r \cdot \rho_{L} \cdot c_{L} \cdot h_{L}} \cdot\left(\frac{1}{F}+1.274 \cdot\left(\frac{t_{s}}{r}\right) \cdot\left(t^{+}\right)^{-1 / 3}\right) \\
& F=\left\{\begin{aligned}
2 \cdot\left(\frac{t^{+}}{\pi}\right)^{1 / 2}-\frac{t^{+}}{\pi} \cdot\left[2-\left(\frac{t^{+}}{4}\right)-\left(\frac{t^{+}}{4}\right)^{2}-\frac{15}{4} \cdot\left(\frac{t^{+}}{4}\right)^{3}\right], & t^{+}<0.6 \\
\frac{8}{3 \cdot \pi}-\frac{1}{2 \cdot\left(\pi \cdot t^{+}\right)^{1 / 2}} \cdot\left[1-\frac{1}{3 \cdot\left(4 \cdot t^{+}\right)}+\frac{1}{6 \cdot\left(4 \cdot t^{+}\right)^{2}}-\frac{1}{12 \cdot\left(4 \cdot t^{+}\right)^{3}}\right], & t^{+} \geq 0.6
\end{aligned}\right\} \\
& t^{+}=\frac{\alpha_{s} \cdot t}{r^{2}}
\end{aligned}
$$

In the above equations, $\dot{T}_{L}$ is the instantaneous temperature rise in the lead core and $h_{L}, r, \rho_{L}, c_{L}$ and $\sigma_{Y, 1}$ are the height, radius, density, specific heat and initial yield stress of the lead core, respectively. $t_{s}$ is the total shim plate thickness, $\alpha_{s}$ and $k_{s}$ are the thermal diffusivity and thermal conductivity of steel, in the same order. $t^{+}$is the dimensionless time, $t$ is the time since the beginning of the motion, and $E_{2}$ is a constant that relates the lead core temperature and yield stress of lead.

The bidirectional bilinear hysteretic model used for modeling of LRBs was developed by Park et al. [17]. The accuracy of this model to represent the behavior of isolators in bidirectional motion was tested and verified [18,19]. According to the model developed by Park et al. [17], coupled solution of motions in the two orthogonal horizontal directions are computed by the following set of equations:

$$
\begin{aligned}
& \left\{\begin{array}{l}
F_{x} \\
F_{y}
\end{array}\right\}=c_{d} \cdot\left\{\begin{array}{l}
\dot{U}_{x} \\
\dot{U}_{y}
\end{array}\right\}+K \cdot\left\{\begin{array}{l}
U_{x} \\
U_{y}
\end{array}\right\}+\left(\sigma_{Y L}\left(T_{L}\right) A_{L}\right) \cdot\left\{\begin{array}{l}
Z_{x} \\
Z_{y}
\end{array}\right\} \\
& Y \cdot\left\{\begin{array}{l}
Z_{x} \\
Z_{y}
\end{array}\right\}=(A \cdot[I]-B \cdot[\Omega]) \cdot\left\{\begin{array}{c}
\dot{U}_{x} \\
\dot{U}_{y}
\end{array}\right\} \\
& {[\Omega]=\left\{\begin{array}{l}
Z_{x}^{2} \cdot\left[\operatorname{sgn}\left(\dot{U}_{x} Z_{x}\right)+1\right] \\
Z_{x} Z_{y}\left[\operatorname{sgn}\left(\dot{U}_{x} Z_{x}\right)+1\right]
\end{array} Z_{y}\left[\operatorname{sgn}\left(\dot{U}_{y} Z_{y}\right)+1\right]\right.} \\
&
\end{aligned}
$$

where $F_{x}$ and $F_{y}$ are the forces and $U_{x}$ and $U_{y}$ are the displacements of the isolators in $x$ and $y$ directions, respectively. $Y$ and $K$ are the yield displacement and post-yield stiffness of the bilinear force-deformation relation of isolators, respectively. $c_{d}$ stands for the energy dissipation of the rubber and $A_{L}$ is the cross-sectional area of the lead core. In Eq. (5), $\sigma_{Y L}\left(T_{L}\right)$ stands for the instantaneous yield stress, $\sigma_{Y L}$, of the lead based on the instantaneous lead core temperature, $T_{L}$, and it is calculated through Eqs. (1)-(4).

Solution of Eqs. (6) and (7) provides a circular interaction surface for the forces $F_{x}$ and $F_{y}$. Here, $Z_{x}$ and $Z_{y}$ are hysteretic dimensionless quantities that account for the direction and the interaction of hysteretic forces and vary between +1 and -1 . In Eq. (6), $A$ and $B$ values should satisfy the relation of $A=2 B$ [19]. In the present study, $A$ and $B$ are chosen as 1 and 0.5 , respectively to assure that the force and displacement vectors are in the same direction. In the above equations, $[I]$ is the unit (identity) matrix, sgn stands for the signum function and overdot means differentiation with respect to time. 


\section{RESPONSE SPECTRA FOR DESIGN OF SEISMIC ISOLATION UNITS}

Design of the seismic isolation units in the Erzurum Hospital was performed in accordance with a sitespecific response spectrum. Since the Erzurum Hospital is only $4 \mathrm{~km}$ away from the Erzurum Fault, a site-specific response spectrum developed by Durukal and Erdik [20] was used in design of seismic isolation units. The response spectrum for maximum considered earthquake (MCE) was developed for a scenario motion with a magnitude of 6.7 and a closest distance to fault rupture of $4 \mathrm{~km}$. The local site condition is classified as very dense soil and soft rock. Corresponding spectral accelerations for MCE are given in Table 2 for 5\% damping (see Figure 6).

Table 2. Spectral ordinates for MCE level motion

\begin{tabular}{|r|c|c|c|c|c|c|c|c|c|}
\hline Period (s) & 0.0 & 0.2 & 0.3 & 0.5 & 1.0 & 2.0 & 3.0 & 4.0 & 5.0 \\
\hline Spectral Acc. for MCE (g) & 0.68 & 1.58 & 1.58 & 1.35 & 0.90 & 0.50 & 0.32 & 0.25 & 0.20 \\
\hline
\end{tabular}

\section{Selected Ground Motions for NRHA}

In this section, ground motions used to assess the design parameters of the Erzurum Hospital, based on results obtained from NRHA, are introduced. Since the structure is $4 \mathrm{~km}$ away from an active fault the selected ground motions are intended to sustain near-fault characteristics. Moreover, considered ground motions are selected so that the distance from fault is close to $4 \mathrm{~km}$ and the magnitude of motion is close to 6.7 as much as possible. In addition, in order to exclude the discussions that may invade for scaling of ground motions, as-recorded ground motions are used to match the design spectrum. Characteristics of the selected ground motions are presented in Table 3 where PGA and PGV are the peak ground acceleration and the peak ground velocity, respectively. A total of seven pairs of ground motion records are considered so that the assessment of the design parameters can be performed in terms of average values of response quantities. Figure 6 presents the square-root-of-sumof-squares (SRSS) spectra for each ground motion pairs together with their mean value and the design spectrum. Grey solid lines in Figure 6 represent individual SRSS spectra for each record while black solid line stands for the average SRSS spectrum. On the other hand, black dashed line shown in Figure 6 is used to represent the design spectrum.

Table 3. Characteristics of the selected ground motion records

\begin{tabular}{|c|c|c|c|c|c|c|c|}
\hline EQ & Event & Station & Moment & Distance to & Component & PGA & PGV \\
\hline 1 & \multirow{2}{*}{ ChiChi } & \multirow{2}{*}{ TCU065 } & \multirow{2}{*}{7.6} & \multirow{2}{*}{0.6} & \multirow{2}{*}{$\begin{array}{l}\mathrm{W} \\
\mathrm{N}\end{array}$} & 0.81 & 126.2 \\
\hline & & & & & & 0.60 & 7.8 \\
\hline 2 & \multirow{2}{*}{ Erzincan } & \multirow{2}{*}{ Erzincan } & \multirow{2}{*}{6.7} & \multirow{2}{*}{4.4} & \multirow{2}{*}{$\begin{array}{l}\text { NS } \\
\text { EW }\end{array}$} & 0.52 & 83.9 \\
\hline & & & & & & 0.50 & 64.3 \\
\hline 3 & \multirow{2}{*}{ Imperial Valley } & \multirow{2}{*}{ ElCentro Array \#5 } & \multirow{2}{*}{6.5} & \multirow{2}{*}{4.0} & \multirow{2}{*}{$\begin{array}{l}230 \\
140\end{array}$} & 0.38 & 90.5 \\
\hline & & & & & & 0.52 & 46.9 \\
\hline 4 & \multirow{2}{*}{ Imperial Valley } & \multirow{2}{*}{ ElCentro Array \#7 } & \multirow{2}{*}{6.5} & \multirow{2}{*}{0.6} & \multirow{2}{*}{$\begin{array}{l}230 \\
140\end{array}$} & 0.46 & 109.3 \\
\hline & & & & & & 0.34 & 47.6 \\
\hline 5 & \multirow{2}{*}{ Kobe } & \multirow{2}{*}{ KJMA } & \multirow{2}{*}{6.9} & \multirow{2}{*}{1.0} & \multirow{2}{*}{$\begin{array}{l}000 \\
090\end{array}$} & 0.82 & 81.3 \\
\hline & & & & & & 0.60 & 74.3 \\
\hline 6 & \multirow{2}{*}{ Kocaeli } & \multirow{2}{*}{ Yarimca } & \multirow{2}{*}{7.5} & \multirow{2}{*}{4.8} & \multirow{2}{*}{$\begin{array}{l}330 \\
060\end{array}$} & 0.35 & 62.1 \\
\hline & & & & & & 0.27 & 65.7 \\
\hline 7 & \multirow{2}{*}{ Landers } & \multirow{2}{*}{ Lucerne } & \multirow{2}{*}{7.3} & \multirow{2}{*}{2.2} & 260 & 0.73 & 146.5 \\
\hline & & & & & 345 & 0.79 & 32.4 \\
\hline
\end{tabular}




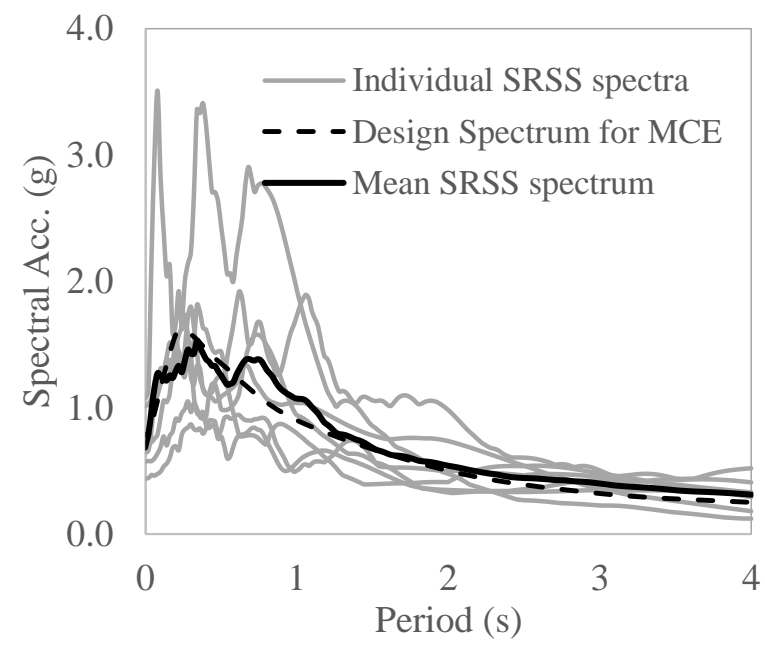

Figure 6. 5\% damped SRSS spectra for selected records and the design spectrum for MCE

\section{Analysis Results}

The success of bounding analyses (lower and upper bound analyses) in providing an envelope for response quantities of the existing seismic isolated hospital is evaluated by a comparative manner. Comparisons are conducted between the cases where a non-deteriorating hysteretic representation is used to idealize the bilinear force-deformation relation of isolators and the case where a deteriorating hysteretic behavior is used to model isolator behavior. It is to be noted that the deterioration in strength of isolators is due to accumulated temperature in the lead core caused by cyclic motion of bearing. The response quantities used in the comparisons are obtained from bidirectional NRHA and are representative of both isolator and superstructure responses namely, maximum isolator displacement (MID) and maximum isolator force (MIF), maximum absolute floor accelerations, and relative story displacements.

\subsection{Comparison of MIDs and MIFs}

Figure 7 presents the isolator displacements in $\mathrm{x}$-direction $\left(\mathrm{D}_{\mathrm{x}}\right)$ versus isolator displacements in $\mathrm{y}$ direction $\left(D_{y}\right)$ while Figure 8 shows the isolator force in $x$-direction $\left(F_{x}\right)$ versus isolator force in $y$ direction $\left(\mathrm{F}_{\mathrm{y}}\right)$ obtained from bidirectional NRHA for ground motion records given in Table 3. In both Figures 7-8, blue and pink lines represent the lower and upper bound cases, respectively whereas green line stands for the case where the effect of lead core temperature on the response of isolator is considered. Figures 7-8 are also tabulated in terms of MIDs and MIFs in Table 4 where MID is calculated as maximum of $\left(\left(D_{x}\right)^{2}+\left(D_{y}\right)^{2}\right)^{1 / 2}$ and MIF is defined as maximum isolator force in any direction, $\max \left(\mathrm{F}_{\mathrm{x}}, \mathrm{F}_{\mathrm{y}}\right)$. In Table $4, \mathrm{LB}$ and UB represent the lower bound and upper bound analyses, respectively. On the other hand, TI stands for the cases where the rise in lead core temperature is included.

Based on the average of MIDs presented in Table 4, it can be said that bounding analysis is satisfactory in providing a safe envelope for isolator displacement. From NRHA, MIDs obtained for LB, UB and TI cases are $665 \mathrm{~mm}, 476 \mathrm{~mm}$, and $641 \mathrm{~mm}$, respectively. It is clear that, lower bound analysis results in larger estimations in terms of mean isolator displacements compared to the temperature effect included cases. In an average sense, the amount of overestimation provided by bounding analyses (compared to TI case) is approximately 3.5\%. However, when individual analysis results are considered, there are two cases namely, Chi Chi TCU065 and Imperial Valley Array \#7 of El Centro records, where bounding analysis is inadequate to provide an envelope for MID. This clearly indicates that bounding analyses may not succeed in providing an envelope for individual 
ground motions. Table 4 is also used to evaluate the success of bounding analysis in providing conservative estimates for MIF. The mean values of MIFs obtained from NRHA for LB, UB, and TI cases are $963 \mathrm{kN}, 1129 \mathrm{kN}$, and $969 \mathrm{kN}$, respectively. As a result, it can be said that bounding analyses can be used to get an envelope in terms of MIF. However, there is one exceptional ground motion pair (ChiChi-TCU065) where MIF obtained from TI case is slightly greater than that of UB. Observations from Figures 7-8 and Table 4 reveal that bounding analyses should be complemented with the temperature dependent response of LRBs.

\subsection{Comparison of Maximum Absolute Floor Accelerations}

In this section, the response of the Erzurum Hospital obtained from bounding analyses is studied in terms of absolute floor accelerations in comparison to TI case. The absolute accelerations in $\mathrm{x}$ and $\mathrm{y}$ directions at any floor level, $a_{x i}$ and $a_{y i}$, are defined as $a_{x i}=\ddot{x}_{i}+\ddot{z}_{x}$ and $a_{y_{i}}=\ddot{y}_{i}+\ddot{z}_{y}$, where $\ddot{x}_{i}$ and $\ddot{y}_{i}$ are the relative accelerations of $\mathrm{i}^{\text {th }}$ floor in $\mathrm{x}$ and $\mathrm{y}$ directions, respectively and $\ddot{z}_{x}$ and $\ddot{z}_{y}$ are the ground accelerations in the corresponding directions. The maximum absolute floor acceleration is defined as the maximum of $\left(\left(a_{x i}\right)^{2}+\left(a_{y i}\right)^{2}\right)^{1 / 2}$. To assess the success of predictions of bounding analysis, the maximum absolute floor accelerations are depicted in Figure 9 for individual ground motion pairs whereas Figure 10 presents the average values. Figure 9 reveals that floor accelerations obtained from TI case, do not possess a general trend compared to results obtained from lower and upper bound analyses. On the other hand, when averages of maximum absolute floor accelerations are of concern, Figure 10 indicates that TI case result in accelerations bounded within a band provided by the bounding analyses. Figure 10 clearly shows that LB and TI cases give close results compared to UB case. As a result, in average, it can be concluded that bounding analysis is efficient in providing an envelope for the absolute floor accelerations of the superstructure. However, it is to be noted that there may be exceptional cases where such generalization is not valid as in the case of $\mathrm{EQ \# 1.} \mathrm{As} \mathrm{shown} \mathrm{in}$ Figure 9(a), TCU065 (EQ\#1) record results in larger absolute floor accelerations at almost all floor levels than the ones for bounding analyses. The maximum absolute floor accelerations obtained from TI case are almost identical to each other and equals to $0.38 \mathrm{~g}$ (Figure 9(a)). On the other hand, both LB and UB analyses result in maximum absolute floor accelerations of $0.34 \mathrm{~g}$ up to 7 stories (Figure 9(a)). 
Özdemir and Avşar / Anadolu Univ. J. of Sci. and Technology A-Appl. Sci. and Eng. 18 (1) - 2017
a) EQ\#1
b) $\mathrm{EQ \# 2}$
c) $\mathrm{EQ \# 3}$

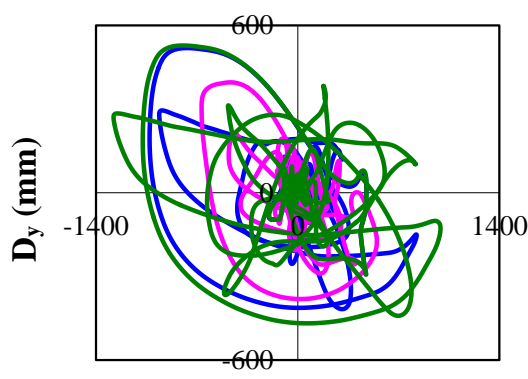

c) $\mathrm{EQ \# 4}$

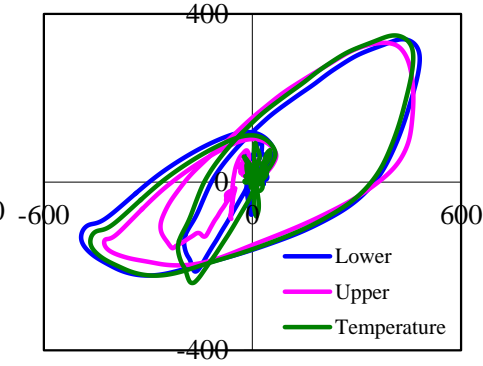

$\mathbf{D}_{\mathbf{x}}(\mathbf{m m})$

d) EQ\#5

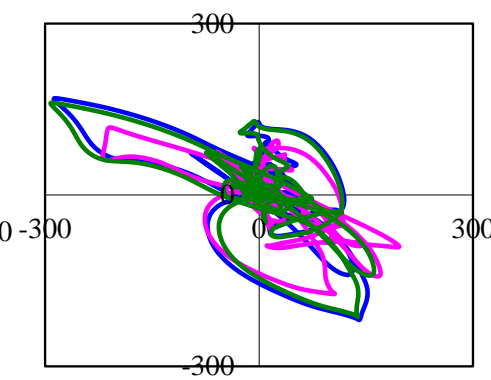

$\mathbf{D}_{\mathbf{x}}(\mathbf{m m})$

f) $E Q \# 7$

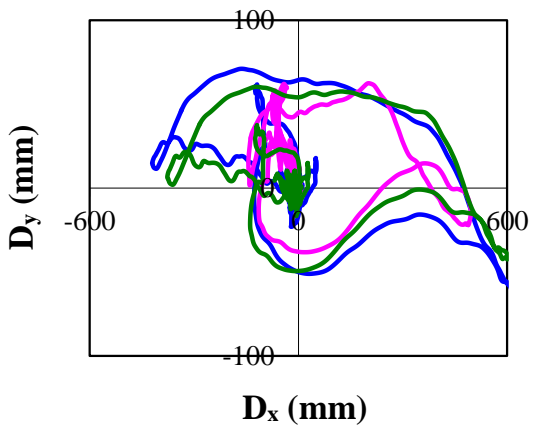

Figure 7. $D_{x}$ versus $D_{y}$ plots for the considered ground motions 
Özdemir and Avşar / Anadolu Univ. J. of Sci. and Technology A-Appl. Sci. and Eng. 18 (1) - 2017
a) EQ\#1
b) $\mathrm{EQ} \# 2$
c) $\mathrm{EQ} \# 3$

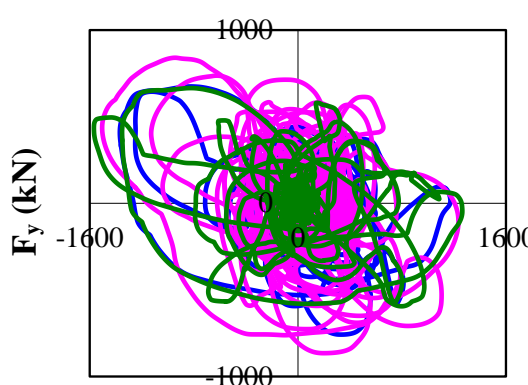

c) $\mathrm{EQ \# 4}$

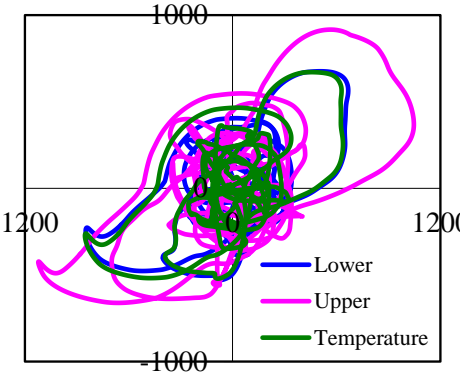

$\mathbf{F}_{\mathrm{x}}(\mathbf{k N})$

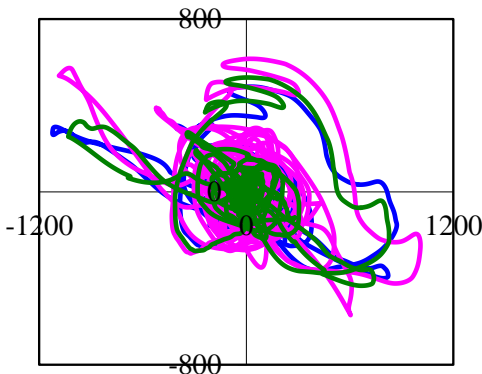

e) EQ\#6

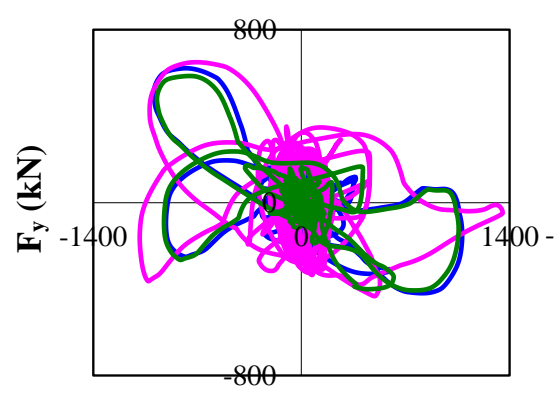

d) $\mathrm{EQ} \# 5$

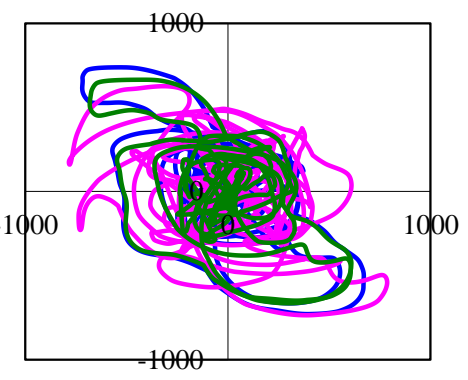

$\mathbf{F}_{\mathbf{x}}(\mathbf{k N})$

f) $\mathrm{EQ \# 7}$

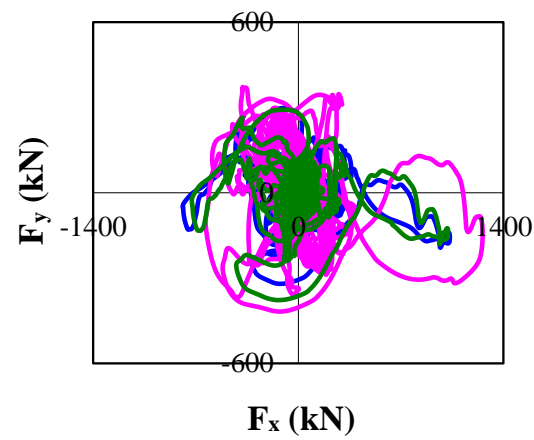

Figure 8. $F_{x}$ versus $F_{y}$ plots for the considered ground motions

Table 4. MIDs and MIFs obtained from NRHA performed under bidirectional earthquake excitations.

\begin{tabular}{|c|c|c|c|c|c|c|}
\hline \multirow{2}{*}{ EQ \# } & \multicolumn{3}{|c|}{$\begin{array}{l}\text { MIF } \\
\text { (kN) }\end{array}$} & \multicolumn{3}{|c|}{$\begin{array}{c}\text { MID } \\
(\mathbf{m m})\end{array}$} \\
\cline { 2 - 7 } & LB & UB & TI & LB & UB & TI \\
\hline $\mathbf{1}$ & 1368 & 1504 & 1567 & 1072 & 745 & 1307 \\
\hline $\mathbf{2}$ & 849 & 1122 & 853 & 572 & 534 & 560 \\
\hline $\mathbf{3}$ & 1123 & 1086 & 1032 & 724 & 453 & 662 \\
\hline $\mathbf{4}$ & 1082 & 1354 & 1058 & 735 & 542 & 745 \\
\hline $\mathbf{5}$ & 544 & 795 & 568 & 333 & 241 & 333 \\
\hline $\mathbf{6}$ & 738 & 786 & 682 & 587 & 319 & 514 \\
\hline $\mathbf{7}$ & 1034 & 1258 & 1022 & 631 & 496 & 604 \\
\hline Mean & 963 & 1129 & 969 & 665 & 476 & 641 \\
\hline
\end{tabular}


Özdemir and Avşar / Anadolu Univ. J. of Sci. and Technology A-Appl. Sci. and Eng. 18 (1)- 2017

a) EQ\#1

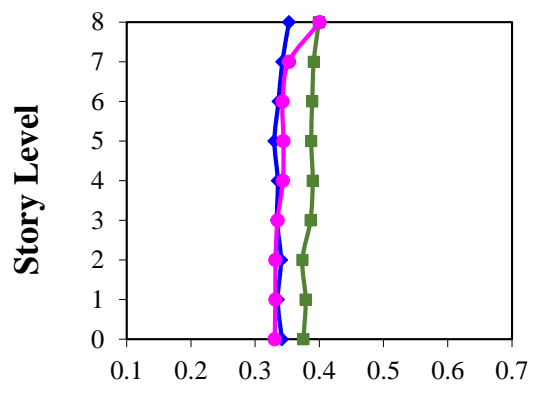

c) $\mathrm{EQ \# 4}$

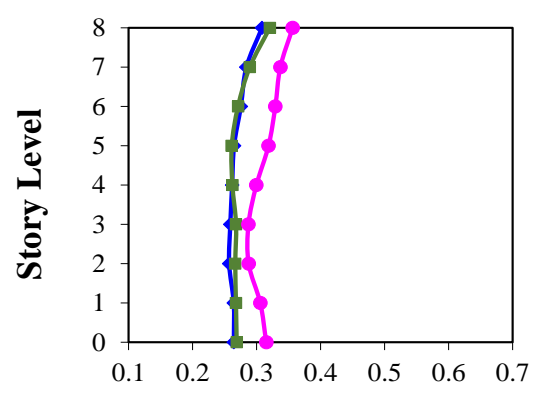

b) $\mathrm{EQ \# 2}$

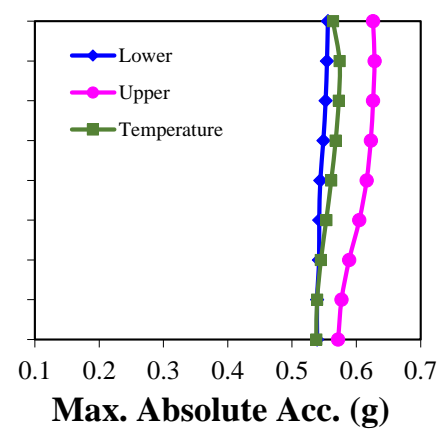

d) EQ\#5

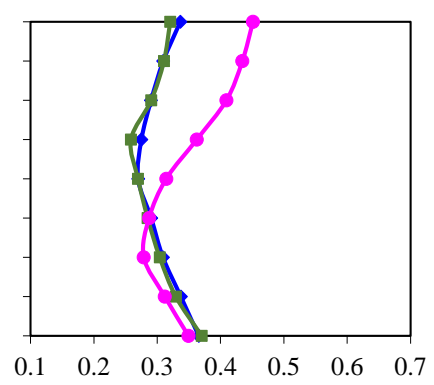

Max. Absolute Acc. (g)

f) $\mathrm{EQ \# 7}$

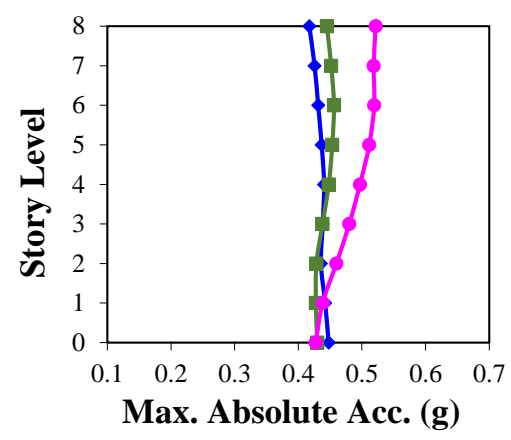

c) $\mathrm{EQ} \# 3$

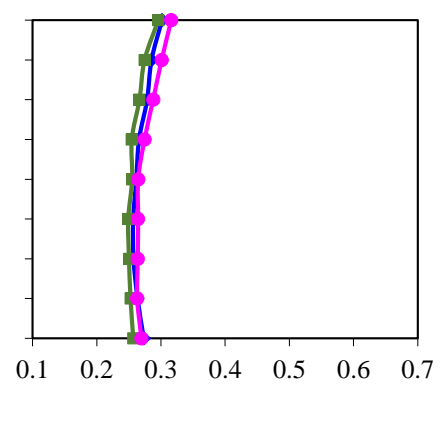

e) EQ\#6

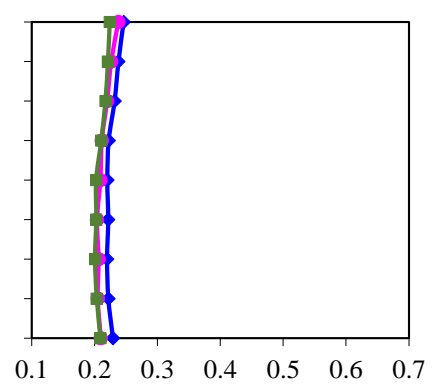

Figure 9. Maximum absolute floor accelerations for individual earthquake excitations

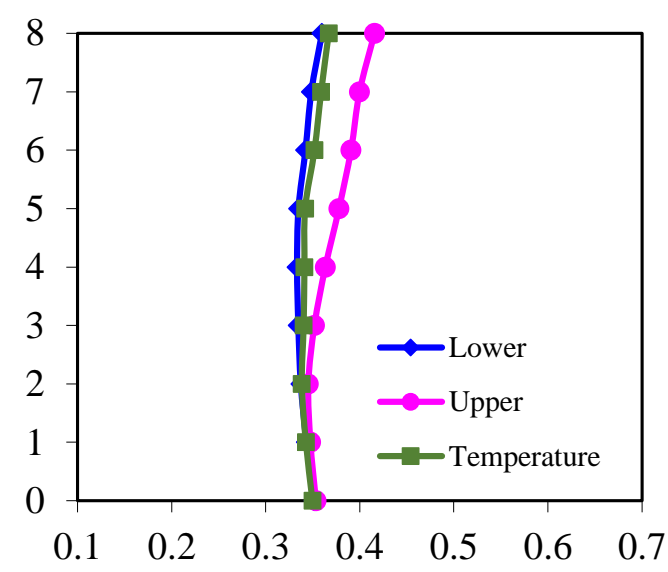

Figure 10. Averages of maximum absolute floor accelerations 
a) EQ\#1

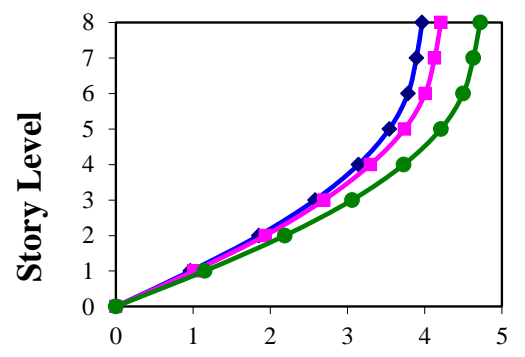

c) $\mathrm{EQ} \# 4$

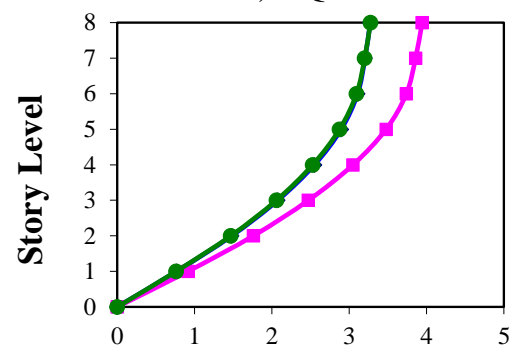

b) EQ\#2

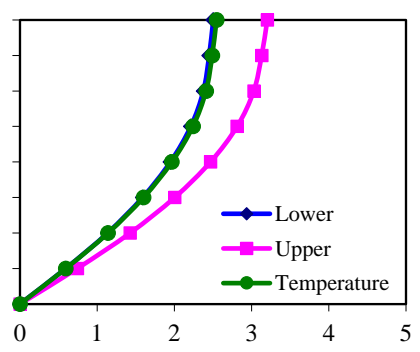

Relative Displacement (mm)

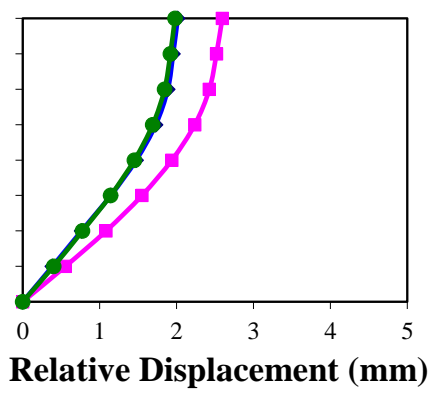

f) $\mathrm{EQ \# 7}$

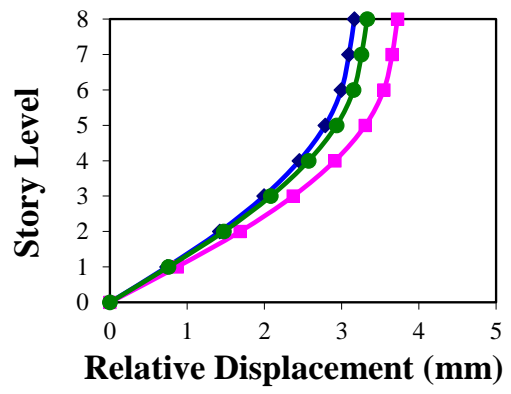

c) $\mathrm{EQ \# 3}$

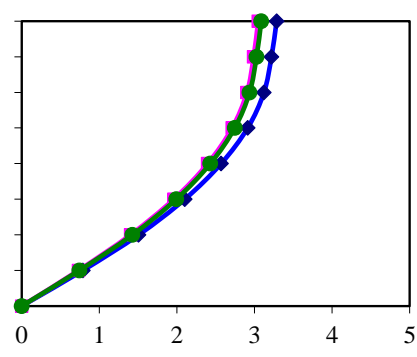

e) EQ\#6

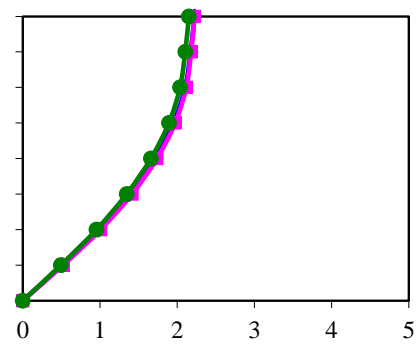

Figure 11. Maximum story displacements relative to isolation level.

\subsection{Comparison of Relative Story Displacements}

This section aims to evaluate the efficiency of bounding analysis in estimation of relative story displacements of the Erzurum Hospital in a comparative manner. For this purpose, relative story displacements obtained from cases, where both deteriorating and non-deteriorating hysteresis curves are used to idealize the LRB behavior, are compared accordingly. Here, the term "relative displacement" is used to define the displacement of each floor relative to isolation level and is determined as maximum of $\left(U_{x i}-U_{x}\right)$ and $\left(U_{y i}-U_{y}\right)$ where $U_{x i}$ and $U_{y i}$ are the story displacements, $U_{x}$ and $U_{y}$ are the isolator displacements in $\mathrm{x}$ and y directions, respectively. Figure 11 presents the maximum relative displacements at each story level for individual ground motion records while Figure 12 gives the corresponding average values. It is evident that bounding analysis is generally satisfactory to provide an envelope for superstructure response in terms of relative story displacements except for the EQ\#1 ground motion record. Similar to variation in maximum absolute floor accelerations presented in Figure 9(a), the relative story displacement demand for the TCU065 (EQ\#1) record for TI case is larger than the demands obtained by bounding analyses (Figure 11(a)). Figure 12 indicates that the results obtained from LB case are almost identical to those of TI case. 


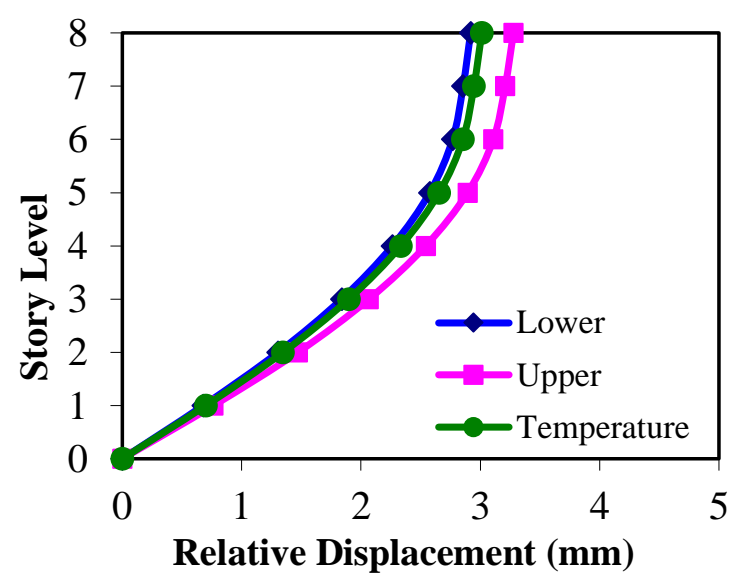

Figure 12. Averages of maximum relative story displacements.

\section{CONCLUSIONS}

This paper investigated the effectiveness of performing bounding analysis to estimate the response quantities of both isolators and superstructure in an LRB isolated structure. The success of bounding analysis is tested in comparison to results obtained from nonlinear response history analyses where a deteriorating hysteretic representation (TI case) was used to idealize the LRBs under consideration. Analyses were conducted with near field ground motions representative of MCE level spectrum. The deterioration in strength of LRBs is due to temperature rise in the lead core accumulated during cyclic motion that the isolator undergoes. On the other hand, bounding analyses were performed with nondeteriorating hysteretic representations with corresponding values for lower and upper bound analyses (LB and UB cases). To achieve the goal of the present study, an existing seismic base isolated hospital, where the isolation units are composed of both LRBs and NRBs, is considered and subjected to ground motions compatible with the design spectra. The analyzed seismic base isolated hospital building comprised of 386 isolators where 63 of them are NRBs and the rest are LRBs with 4 different geometries. During the comparisons, it is assumed that the deteriorating hysteretic behaviors employed in the analyses constitute the actual behaviors of LRBs that may be experienced during a cyclic motion.

It is to be noted that the results observed in the present study are obtained from the nonlinear response history analyses conducted with ground motions used as is. In other words, employed ground motions are selected so that none of the records were scaled up to match the design spectra. This is especially crucial when lead core heating effect is of concern. Since, the heat generated at the lead core is a function of the amplitude of motion, scaling up the records may result in unrealistically high isolator displacements. To avoid such response, all of the selected records have a scale factor of 1.0 in MCE level. The following conclusions are derived based on the comparisons in terms of MIDs, MIFs, maximum absolute floor accelerations and relative story displacements.

- In an average sense, it is found that bounding analyses fulfill their intended purpose to provide conservative estimates for MIDs compared to TI case. However, there may be motions where MID obtained from TI analyses are greater than that of bounding analyses as in the two of ground motions considered in this study. Such behavior should be considered carefully in the design of isolated structures and bounding analyses should be complemented with further analyses where lead core heating effect is considered.

- Bounding analysis produces overestimated maximum isolator forces compared to the actual case where lead core heating is accurately included in the analyses. Such observation is found to be 
valid for both average and individual cases for the considered ground motions. It is also found that isolator forces obtained from actual response is very close to those of lower bound cases.

- It is observed that bounding analysis is also efficient in prediction of superstructure response when the mean results are concerned. The maximum absolute floor accelerations obtained from analyses, where temperature effect on the response of LRBs is considered, show that floor accelerations vary in a narrow band bounded by the results obtained from bounding analyses. In an average sense, it can be said that lower bound analysis seems to provide almost identical estimates for the actual maximum absolute accelerations obtained in TI case.

- Bounding analysis is also found to be satisfactory in providing an envelope for the relative story displacements of the superstructure under consideration. Similar to the case for absolute floor accelerations, lower bound analysis gives almost the same displacements at the story levels relative to isolation level in comparison to actual response of isolators.

- Although the mean absolute floor accelerations and the mean relative story displacements obtained from TI case are within a boundary provided by the bounding analyses results, there may be individual ground motions records like the TCU065 record in this study, which do not satisfy this condition. Therefore, bounding analyses should be complemented by additional analyses considering the lead core heating phenomena.

\section{ACKNOWLEDGMENTS}

"Kare Engineering Consultancy and Trade Limited Co." is greatly appreciated for providing the test results of the LRBs and the blue prints used in the construction of Erzurum Hospital.

\section{REFERENCES}

[1] Robinson WH. Lead-rubber hysteretic bearings suitable for protecting structures during earthquakes. Earthquake Eng Struc 1982; 10: 593-604.

[2] American Association of State Highway and Transportation Officials (AASHTO). Guide specifications for seismic isolation design. Washington, 1999.

[3] American Society of Civil Engineers (ASCE). Minimum design loads for buildings. ASCE/SEI-710 Reston, 2010.

[4] Kalpakidis IV, Constantinou MC. Effects of heating on the behavior of lead-rubber bearing. I:Theory. J Struct Eng 2009; 135: 1440-1449.

[5] Kalpakidis IV, Constantinou MC. Effects of heating on the behavior of lead-rubber bearing. II:Verification of theory. J Struct Eng 2009; 135: 1450-1461.

[6] Ozdemir G, Avsar O, Bayhan B. Change in response of bridges isolated with LRBs due to lead core heating. Soil Dyn Earthq Eng 2011; 31: 921-929.

[7] Ozdemir G, Dicleli M. Effect of lead core heating on the seismic performance of bridges isolated with LRB in near fault zones. Earthquake Eng Struc 2012; 41: 1989-2007.

[8] Ozdemir G. Formulations for equivalent linearization of LRBs in order to incorporate effect of lead core heating. Earthq Spectra 2015; 31:317-337.

[9] Ozdemir G. Lead core heating in LRBs subjected to bidirectional ground motion excitations in various soil types. Earthquake Eng Struc 2014; 43: 267-285. 
Özdemir and Avşar / Anadolu Univ. J. of Sci. and Technology A-Appl. Sci. and Eng. 18 (1) - 2017

[10] Ozdemir G, Bayhan B. Response of an isolated structure with deteriorating hysteretic isolator model. Res Eng Struct Mat 2015; 1: 1-10.

[11] Providakis CP. Effect of supplemental damping on LRB and FPS seismic isolators under nearfault ground motions. Soil Dyn Earthq Eng 2009; 29: 80-90.

[12] Yang TY, Konstantinidis D, Kelly JM. The influence of isolator hysteresis on equipment performance in seismic isolated buildings. Earthq Spectra 2010; 26: 275-293.

[13] Erdik M. Seismic isolation for buildings. 6th National Conference on Earthquake Engineering; 16-20 October 2007; Istanbul, Turkey.

[14] Ministry of Public Works and Settlement, General Directorate of Disaster Affairs. Earthquake Zoning Map of Turkey, 96/8109, 1996.

[15] Open System for Earthquake Engineering Simulation (OpenSees). Version: 2.1.0. University of California, Pacific Earthquake Engineering Research Center, Berkeley, California, 2001.

[16] Erdik M, Constantinou MC. Design and analysis of seismic isolation system for Erzurum Hospital, Turkey. Technical Report, Ankara, Turkey, 2005.

[17] Park YJ, Wen YK, Ang AH. Random vibration of hysteretic systems under bi-directional ground motions. Earthquake Eng Struc 1986; 14: 543-557.

[18] Nagarajaiah S, Reinhorn AM, Constantinou MC. Nonlinear dynamic analysis of threedimensional base isolated structures (3D-BASIS). Technical Report NCEER-89-0019, National Center for Earthquake Engineering Research, State University of New York at Buffalo, 1989.

[19] Mokha AS, Constantinou MC, Reinhorn AM. Verification of friction model of teflon bearings under triaxial load. J Struct Eng 1993; 119: 240-261.

[20] Durukal E, Erdik M. Characterization of strong ground motion for the design of seismically isolated structures in near fault conditions. 4th World Conference on Structural Control and Monitoring; 11-13 July 2006; San Diego, US. 